\title{
Rotor Position Estimation for a Switched Reluctance Machine from Phase Flux Linkage
}

\author{
D.Susitra ${ }^{1}$, S.Paramasivam ${ }^{2}$ \\ ${ }^{1}$ Research Scholar, faculty of Electrical and Electronics Engineering, Sathyabama University, Chennai 600 \\ 119, India \\ ${ }^{2}$ R\&D Head, ESAB Group, Sriperumbudur Taluk, Kanchipuram District, 602 105, India
}

\begin{abstract}
This paper presents a rotor position estimation technique for a $6 / 4$ switched reluctance machine based on Adaptive Neuro fuzzy Inference System (ANFIS). This technique is applied for modelling the nonlinear rotor position of SRM using the magnetization characteristics of the machine. ANFIS has a strong nonlinear approximation ability which could be used for nonlinear modelling and its real time implementations. In this paper, the best features of ANFIS is utilised to develop the computationally efficient rotor position model $\theta(I, \psi)$ for SRM. Mathematical model for $\theta(I, \psi)$ using ANFIS has been successfully arrived, tested and presented for various values of phase currents (Iph) and phase flux linkage( $\psi$ ) of a non linear SRM. It is observed that ANFIS is highly suitable for rotor position $\theta(I, \psi)$ modelling of SRM which is tested to be in good agreement with the training and checking data used for modelling.
\end{abstract}

Keywords: Rotor position estimation model, Adaptive neuro-fuzzy inference system (ANFIS), Switched reluctance machine (SRM), Phase flux linkage.

\section{Introduction}

The Switched reluctance machine (SRM) can be operated as a motor/generator which is the subject of interest by many researchers in the field of electrical machines for the last few decades. Many research papers have concluded that Switched Reluctance motor (SRM) has proved to be a valid alternative to the classical motors in many industrial applications. The magnetization characteristics of SRM is highly non-linear [1] owing to the fact that the working zone of SRG is a highly saturated magnetic circuit which together with the effects of eddy currents, magnetic hysteresis and its special double salient structure and non uniform air gap makes the flux linkage and torque as the non-linear functions of both the current (Iph) and rotor position( $\theta$ ). Establishing this high precision nonlinear mapping between $\psi(\mathrm{I}, \theta)$,current $(\mathrm{Iph})$ and rotor position $(\theta)$ are the base to model the machine accurately for the analysis and control of any SRM based system. The electromagnetic characterization of SRM has a direct impact on the electrical analysis, design and application. For the successful and reliable operation of the machine, it is essential to estimate its rotor position accurately. All of the proposed literatures either use the sensor less indirect rotor position estimation or using the sensors in the rotor shaft. Various methods of indirect rotor position estimation based on different techniques have been published in the past literatures. A comprehensive review of the existing indirect rotor position detection techniques in SRM was discussed in [2]. Most of these techniques require manipulating the unexcited phase [3]-[6].In [7] magnetization data are used for rotor position estimation. Another method is observer based approach [8] but these methods are affected due to the magnetic non linearities of the machine. Literature [9] reports on a fuzzy based motor model wherein many fuzzy algorithms are involved to predict rotor position estimation of SRM. Many publications have reported using artificial neural network techniques for position estimation [10] - [14]. This paper uses Adaptive Neuro Fuzzy Inference System (ANFIS) to estimate the rotor position for a $6 / 4$ pole SRM from its phase flux linkage. This paper is organised as follows. Section II presents the mathematical model of SRM and the necessity of rotor position estimation. Section III presents the rotor position estimation of SRM using ANFIS. Comparison of ANFIS based rotor position estimation model with the actual data are discussed in Section IV and the concluding remarks are presented in Section V.

\section{Mathematical model of SRG and the necessity of rotor position estimation}

A Switched Reluctance Motor (SRM) is a rotating electric machine where both stator and rotor have salient poles as shown in Fig. 1. The stator winding comprises a set of coils, each of which is wound on a pole. SRM's differ in the number of phases wound on the stator. Each of them has a certain number of suitable combinations of stator and rotor poles. The individual phases are sequentially excited such that the motor rotates in the desired direction. The current pulses are to be applied to the phase windings at the appropriate rotor position relative to the excited phase for effective control. 
The inductance profile of SRM varies depending on the magnitude of the excited phase current and the relative position of the rotor with respect to the stator pole axis. In an ideal machine with equal stator and rotor pole axis the variation is triangular shaped when the saturation of the core and leakage fluxes are neglected. In a practical SRM the variation of inductance is nonlinear. It is maximum when the stator and rotor poles are coincident, which is referred as the aligned position. Minimum inductance occurs when the rotor inter polar axis coincides with the excited stator pole axis. This position is referred as the unaligned position. All other positions are referred as intermediate positions. When a particular stator phase is excited, the rotor pole nearer to it tends to align with the excited pole, thus producing a torque. Thereafter the amount of torque developed depends on the rate of change of inductance with rotor position and also magnitude of the excited current. Successful and reliable operation of SRM requires a controller, power converter and position sensors. SRM is a highly nonlinear rotating electrical machine, so a non-linear theory describing the behavior of SRM has to be developed. Based on this non-linear theory, a mathematical model of SRM is developed, which can be used for simulation and verification of static and dynamic characteristics of SRM.

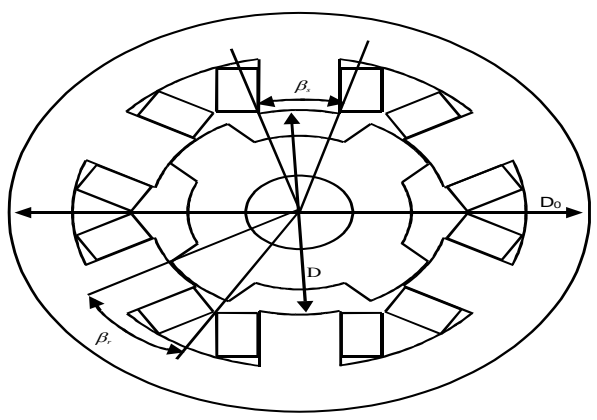

Fig. $1 \quad 6 / 4$ pole SRM

\subsection{Voltage equation}

Fig. 2 illustrates a magnetization characteristics of a $6 / 4$ pole SRM. It is a function between the magnetic flux linkage $(\psi)$, the phase current (i) and the rotor position $(\theta)$. The magnetization characteristic of SRM shows the non-linearity of the motor. When the excitation current is less, the magnetization curve is linear. As the excitation current increases, the relationship between $\psi$ and i become nonlinear as the rotor position changes from unaligned position to the aligned position.

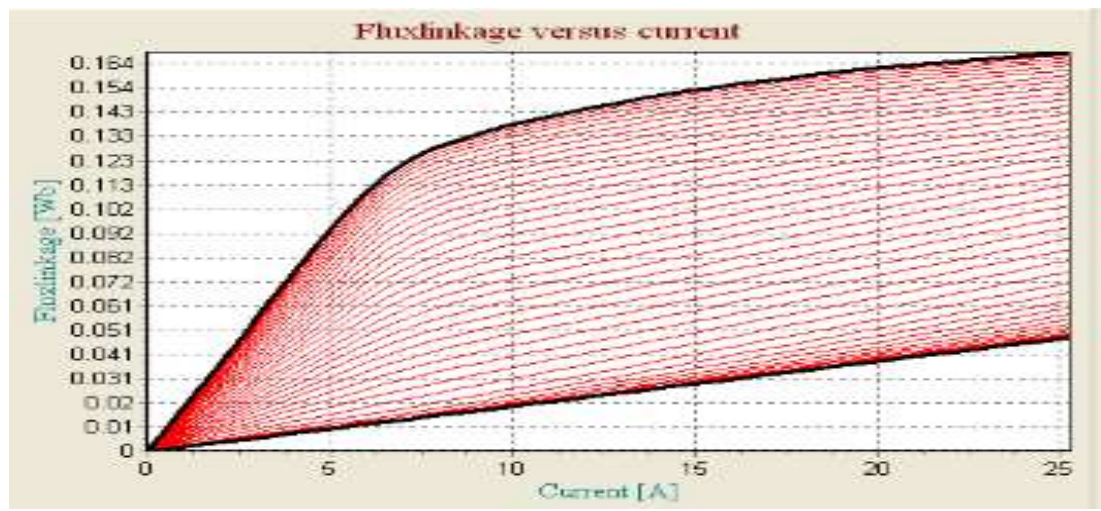

Fig. 2. Magnetization Characteristics of the SRM

The equivalent circuit model of the excited phase of the SRM is shown in Fig.3.

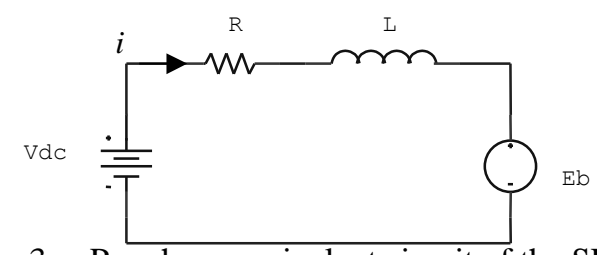

Fig.3. Per phase equivalent circuit of the SRM 
According to Fig. 3, the instantaneous voltage across the terminals of a phase of SRM winding related to the flux linked in the winding is given by,

$$
\begin{aligned}
& V_{p h}(t)=i_{p h}(t) r_{p h}+\frac{d \psi_{p h}\left(i_{p h} \theta_{p h}\right)}{d t} \\
& \psi_{p h}=\int\left(V_{p h}-i_{p h} r_{p h}\right) d t
\end{aligned}
$$

In general, the phase flux linkage and hence the phase inductance in SRM varies as a function of rotor position $\left(\theta_{p h}\right)$ and phase current $\left(i_{p h}\right)$. It is due to doubly salient construction and magnetic saturation effects of the SRM. Hence (1) can be written as

$$
\begin{aligned}
& V_{p h}=i_{p h} r_{p h}+\frac{d\left[L_{p h}\left(i_{p h} \theta\right), i_{p h}\right]}{d t} \\
& V_{p h}=i_{p h} r_{p h}+L_{p h} \frac{d i_{p h}}{d t}+i_{p h} \frac{\partial L_{p h}}{\partial \theta} \frac{d \theta}{d t} \\
& V_{p h}=i_{p h} r_{p h}+\left[L_{p h} \frac{d i_{p h}}{d t}+\frac{1}{2} i_{p h} \frac{d L_{p h}}{d \theta} \omega\right]+\frac{1}{2} i_{p h} \omega \frac{d L_{p h}}{d \theta}
\end{aligned}
$$

\subsection{Torque equation}

When a phase of the SRM is excited by a voltage source, the instantaneous power is obtained by multiplying (5) by $i_{p h}$

$$
\begin{aligned}
& P=V_{p h} i_{p h}=i_{p h}^{2} r_{p h}+i_{p h} L_{p h} \frac{d i_{p h}}{d t}+\omega i_{p h}^{2} \frac{d L_{p h}}{d \theta} \\
& V_{p h} i_{p h}=i_{p h}^{2} r_{p h}+\frac{d}{d t}\left(\frac{1}{2} L_{p h} i_{p h}^{2}\right)+\frac{1}{2} \omega i_{p h}^{2} \frac{d L_{p h}}{d \theta} \\
& V_{p h} i_{p h}=i_{p h}^{2} r_{p h}+\frac{d w_{f}}{d t}+T_{m} \omega
\end{aligned}
$$

where $\quad W_{f} \quad=\frac{1}{2} L_{p h} i_{p h}^{2}$

is the stored energy in the field

$$
\text { and } \quad T_{m}=\frac{1}{2} i_{p h}^{2} \frac{d L_{p h}}{d \theta}
$$

Is the instantaneous torque developed by the energised phase, when the inductance variation is linear? The LHS of the equation (8) represents the instantaneous electrical power supplied to the motor. The first term of the RHS represents the power loss in the phase resistance, the second term represents the derivative of stored energy in the magnetic field and the third term represents the mechanical power developed by the motor.

The inductance profile of SRM is triangular shaped for having equal stator and rotor pole arc combinations, with maximum inductance when it is in an aligned position and minimum inductance when it is in an unaligned position. From the equation (10), the positive torque is produced when the phase is switched on during the rising inductance, i.e. $\frac{d L}{d \theta}>0$, negative torque is produced when the phase is switched on during the falling inductance, i.e. $\frac{d L}{d \theta}<0$ and zero torque is produced when the phase is switched on during the constant inductance, i.e. $\frac{d L}{d \theta}=0$. Hence the SR machine can transform reversible modes of generating and motoring by controlling the power switches in converter circuit. In order to have the required mode of operation (motoring/ 
generating) and to have a proper control over the motor / Generator, the rotor position is very important for accurate control of SR machines in practical applications.

\section{Rotor position estimation of SRM from phase flux linkage using Adaptive neuro -fuzzy inference system}

The ANFIS is Sugeno Adaptive Network Based Fuzzy Inference System (ANFIS) (Jyh-Shing et al.1993). In this section the fuzzy inference system under consideration has two inputs, phase current $(i)$ and phase flux linkage $(\psi)$ and one-output rotor position $\theta(I, \psi)$. Each input has fifteen membership functions. Then the rule base contains two hundred and twenty five fuzzy if-then rules of Takagi and Sugeno's type. The corresponding ANFIS architecture is shown in Fig. 4. The ANFIS network is formed with five layers.

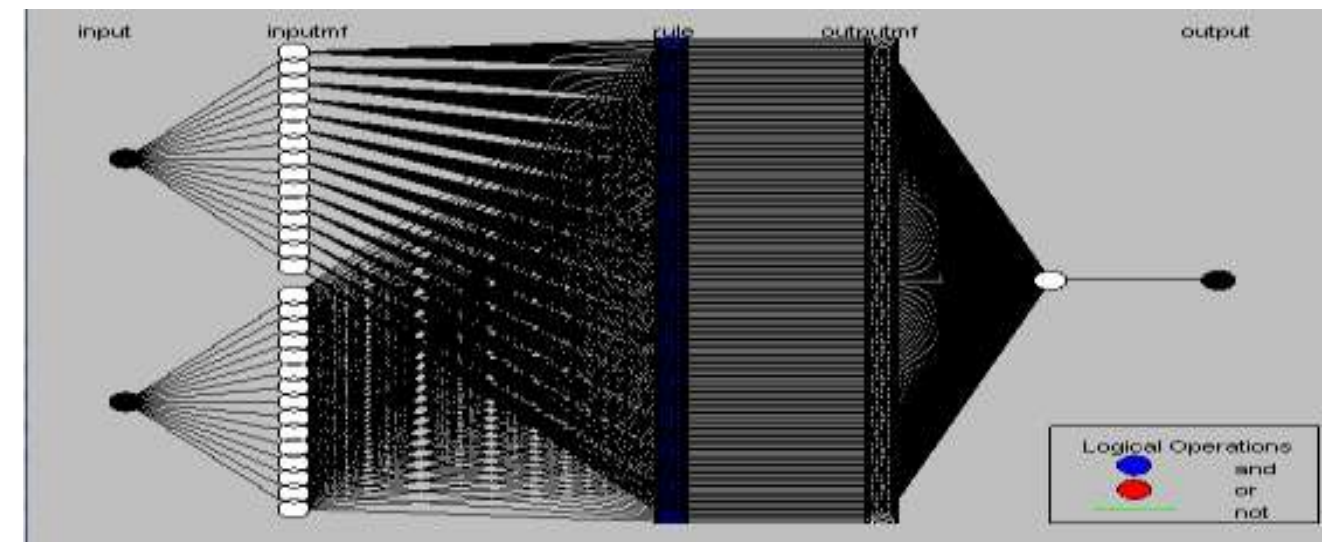

Fig. 4 Structure of ANFIS

Layer 1: In this layer, each input has 15 membership functions. The output of input membership function -1 is $\mathrm{O}_{\mathrm{k} 1}=\boldsymbol{\mu} \boldsymbol{A}_{\boldsymbol{k}}(\boldsymbol{i})$ and the output of input membership function 2 is $\mathrm{O}_{\mathrm{k} 2=} \boldsymbol{\mu} \boldsymbol{B}_{\boldsymbol{k}}(\boldsymbol{\psi}) . \mathrm{A}_{\mathrm{k}}$ and $\mathrm{B}_{\mathrm{k}}$ are the linguistic labels $(\mathrm{mfl}, \mathrm{mf} 2 \ldots \mathrm{mf15}$.) associated with the node functions.The output of the input membership functions specifies the degree to which the given $i$ and $\psi$ satisfies the quantifier $A_{k}$ and $B_{k}$. In this work the triangular shaped membership functions $\mu A_{k}(i)$ and $\mu B_{k}(\psi)$ are used with a maximum equal to 1 and a minimum equal to 0 . The generalized triangular membership function of the current is given by

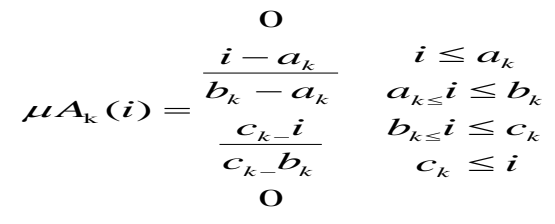

Similarly, the generalized triangular shaped membership function of the phase flux linkage is given by

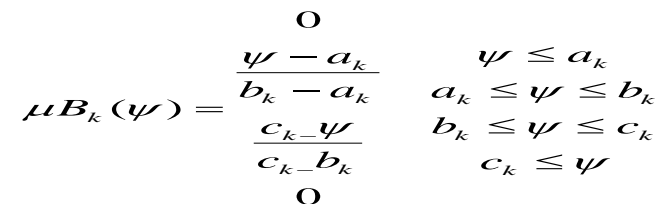

Where $a_{k}, b_{k}$ and $c_{k}$ are the adaptable variables known as parameters. As the values of these parameters changes, the triangular shaped functions vary accordingly, thus exhibiting various forms of membership functions.

Layer 2: It implements the fuzzy AND operator

$$
\mathrm{W}_{\mathrm{k}}=\mu A_{k}(i) \times \mu B_{k}(\psi)
$$

Where $\mathrm{k}=1,2 \ldots 15$;

Layer 3: It acts to scale or normalize the firing strengths. 


$$
\bar{W}_{k}=\frac{W_{\mathrm{k}}}{\sum_{\mathrm{k}=1}^{15} W_{k}}
$$

Layer 4: The output of the fourth layer comprises a linear combination of the inputs multiplied by the normalized firing strength. Output of this layer is given by

$$
\mathrm{O}_{\mathrm{k} 4}=\bar{W}_{\mathrm{k}} \mathrm{f}_{\mathrm{k}}=\bar{W}_{k}\left(\mathrm{~m}_{\mathrm{k}} i+n_{k} \psi+\mathrm{r}_{\mathrm{k}}\right)
$$

Where $\bar{W}_{\mathrm{k}}$ is the output of layer 3 and the modifiable variables $\mathrm{m}_{\mathrm{k}}, \mathrm{n}_{\mathrm{k}}$ and $\mathrm{r}_{\mathrm{k}}$ are known as consequent parameters.

Layer 5: Layer 5 is a simple summation of the outputs of layer 4. Overall output gives the rotor position $\theta$ (i, $\psi)$.

$$
\mathrm{Ok}_{5}=\sum \overline{W_{k}} f_{k}=\frac{\sum_{k} W_{k} f_{k}}{\sum_{k} W_{\mathrm{k}}}
$$

For training the ANFIS model, the magnetization data are taken between an interval of unaligned to aligned rotor position from the magnetization characteristics of [15] and the ranges of the input magnetization data are $0 \leq \mathrm{I} \leq 25 \mathrm{~A} \quad 0 \leq \psi \leq 0.168$ and $0 \leq \theta \leq 45 \mathrm{deg}$.

The ANFIS information are as follows.

ANFIS info:

Number of nodes: 515

Number of linear parameters: 225

Number of nonlinear parameters: 90

Total number of parameters: 315

Number of training data pairs: 182

Number of checking data pairs: 189

Number of fuzzy rules: 225

For the given training data sets, the training has converged at epoch 2. The input membership functions for $i$ and $\psi$ are as shown in fig. 5(a) and 5(b) respectively.

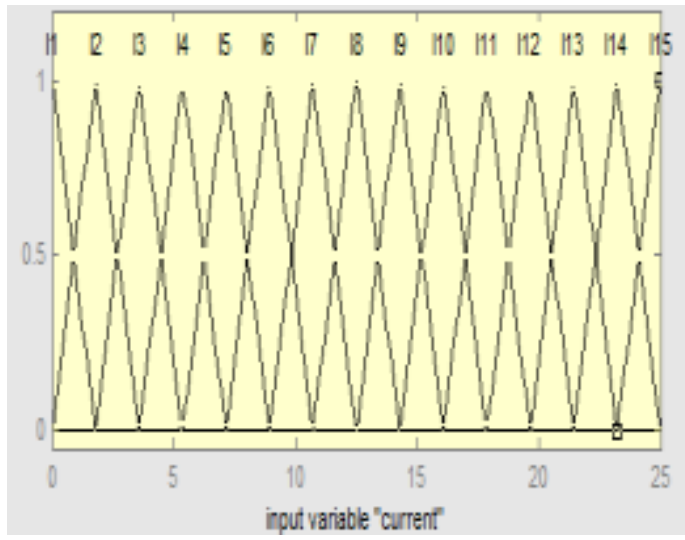

(A)

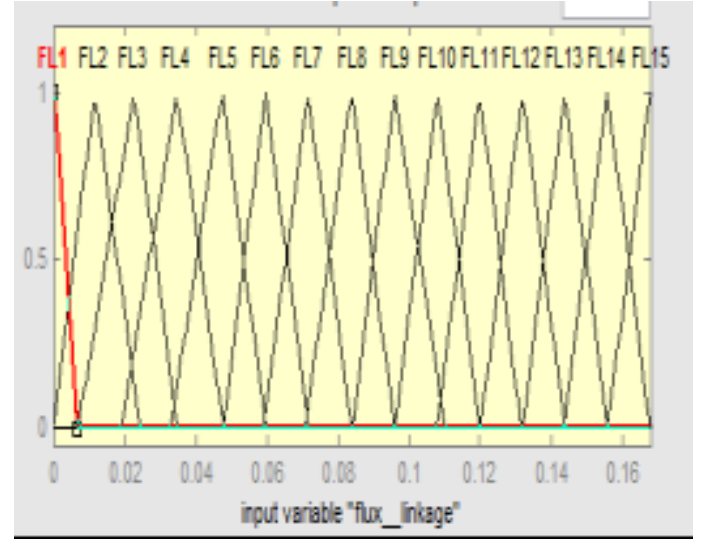

(B)

Fig.5. membership functions for the input variables a) phase current and b) phase flux linkage

Fig.6 shows the ANFIS rule viewer. The first two columns show the membership functions referenced by the two input parameters phase current and phase flux linkage and the third column of plots shows the membership functions referenced by the output variable rotor position. The Rule Viewer interprets the entire fuzzy inference process at once. The non linear mapping surface of the rotor position with respect to phase flux 
linkage and phase current after ANFIS training is shown in fig.8. The developed model using ANFIS has a very simple structure, least training epoch, fast computational speed and characteristic of robustness and presents a superior performance when applied to modelling, prediction and control. It exhibits much faster learning, good convergence properties and accuracy.

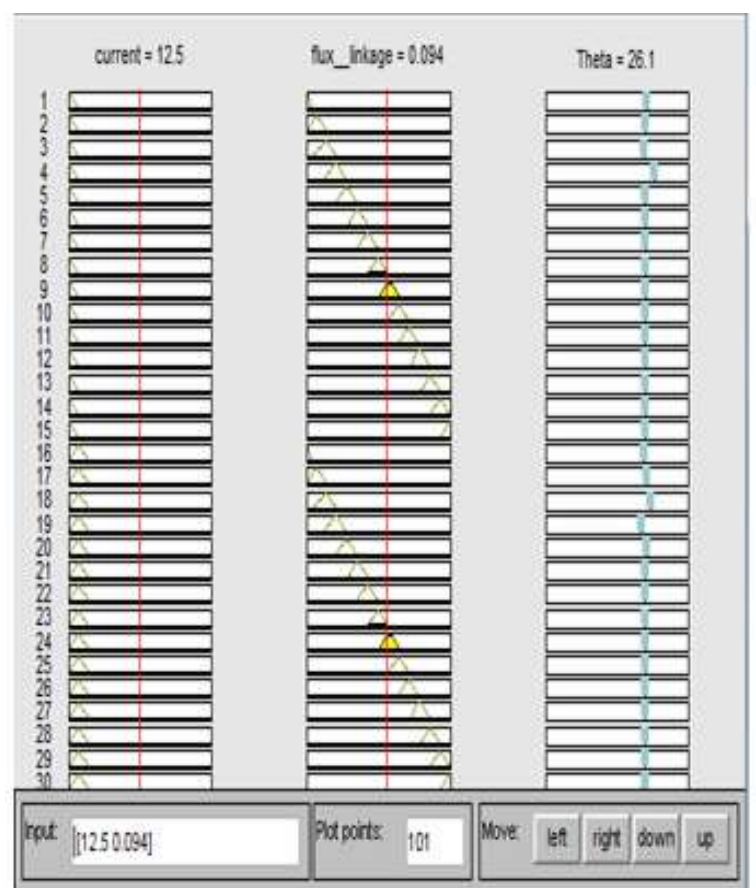

Fig.6. ANFIS rule viewer

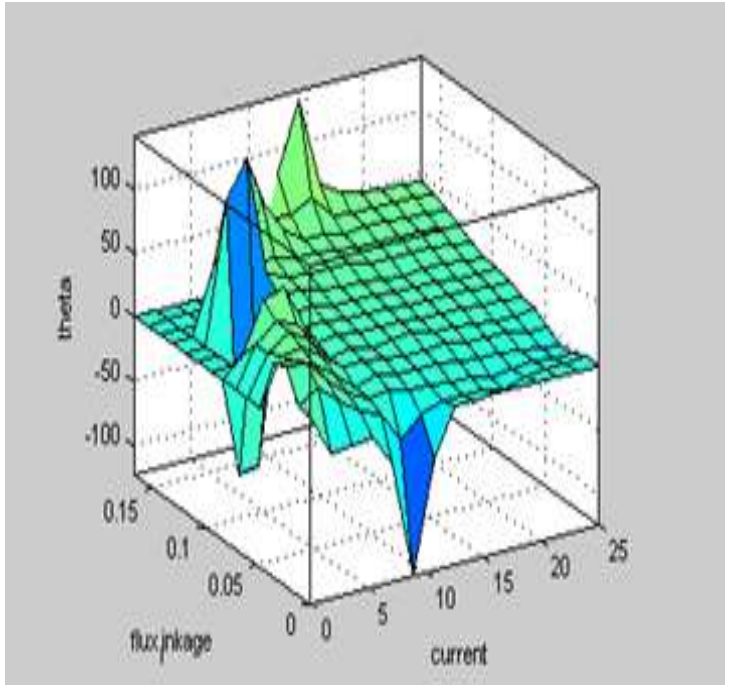

Fig.7. Nonlinear mapping surface of the $\theta(i, \psi)$

\section{Comparison Of ANFIS based rotor position estimation Model with the actual data}

The accuracy of the rotor position model of SRM using ANFIS is validated from fig. 8 which gives the comparison between the actual rotor position values (theta) and the values predicted from ANFIS model. It is clearly visible from fig. 8 that the theta values from the ANFIS estimator are in excellent agreement with the actual theta values for the complete range of test data set.

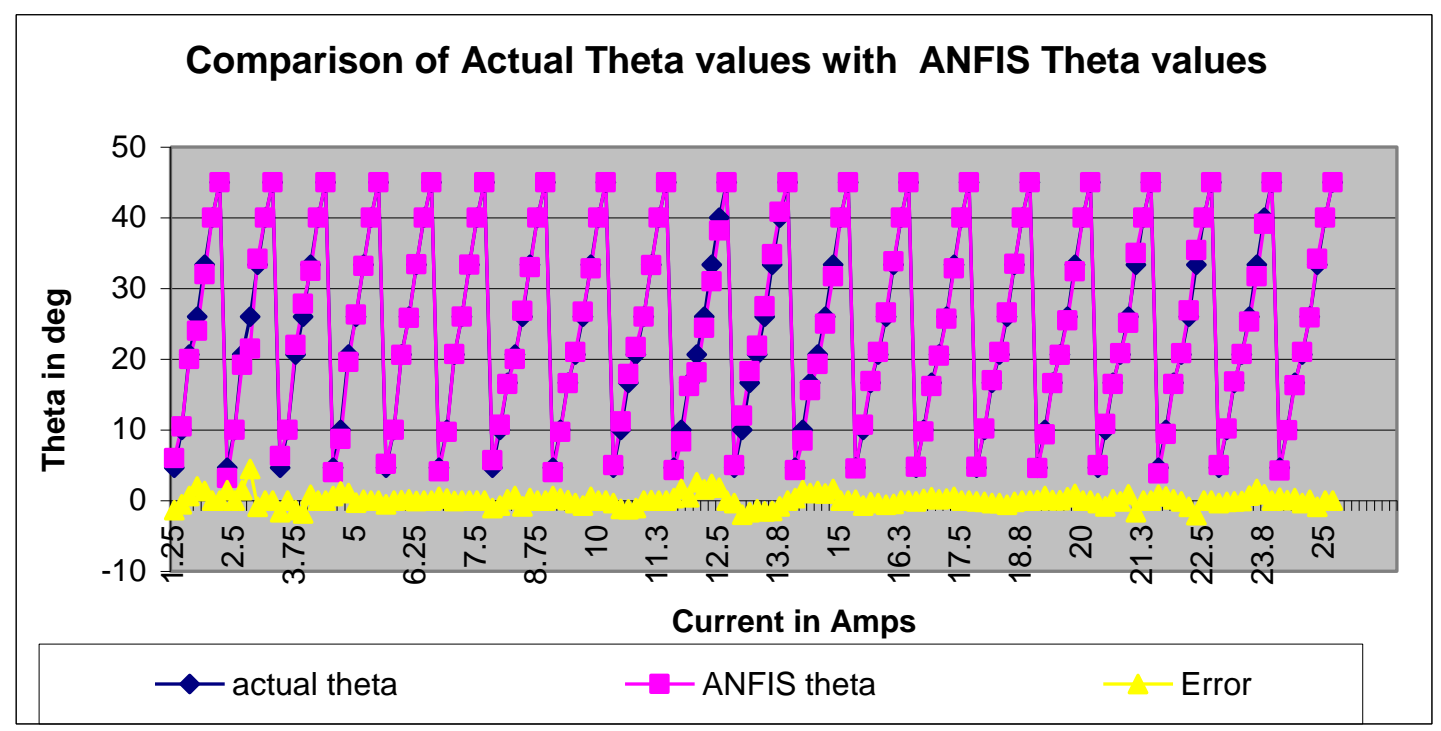

Fig.8 Comparison of actual rotor position with ANFIS model 
The proposed rotor position model based on ANFIS uses the data from the magnetization characteristics of the machine. The error in the ANFIS predicted theta values from the true values for different operating conditions is shown in fig.9. Apart from the graphical representation, root-mean-squared error, mean absolute error and maximum absolute error for both the models at different operating conditions are presented in Table.I. Fig.10 shows the root mean square errors ( $\theta \_$RMSE) and mean absolute errors at various operating conditions. With the careful observation from the comparison charts and error values , it is evident that the ANFIS model is in excellent agreement with the actual results and proves to be the highest accurate model with least errors for the entire set of data range.

TABLE.I

Root-mean-squared error, Mean absolute error and Maximum absolute error at different operating conditions

\begin{tabular}{|c|c|c|c|}
\hline Operating currents & $\psi_{\text {RMSE }}$ & $\psi_{\text {abs mean }}$ & $\psi_{\text {abs max }}$ \\
\hline 5 & 0.69 & 0.49 & 1.3 \\
\hline 10 & 0.42 & 0.32 & 0.7 \\
\hline 15 & 0.41 & 0.3 & 0.69 \\
\hline 20 & 0.4 & 0.28 & 0.65 \\
\hline 25 & 0.38 & 0.26 & 0.62 \\
\hline
\end{tabular}
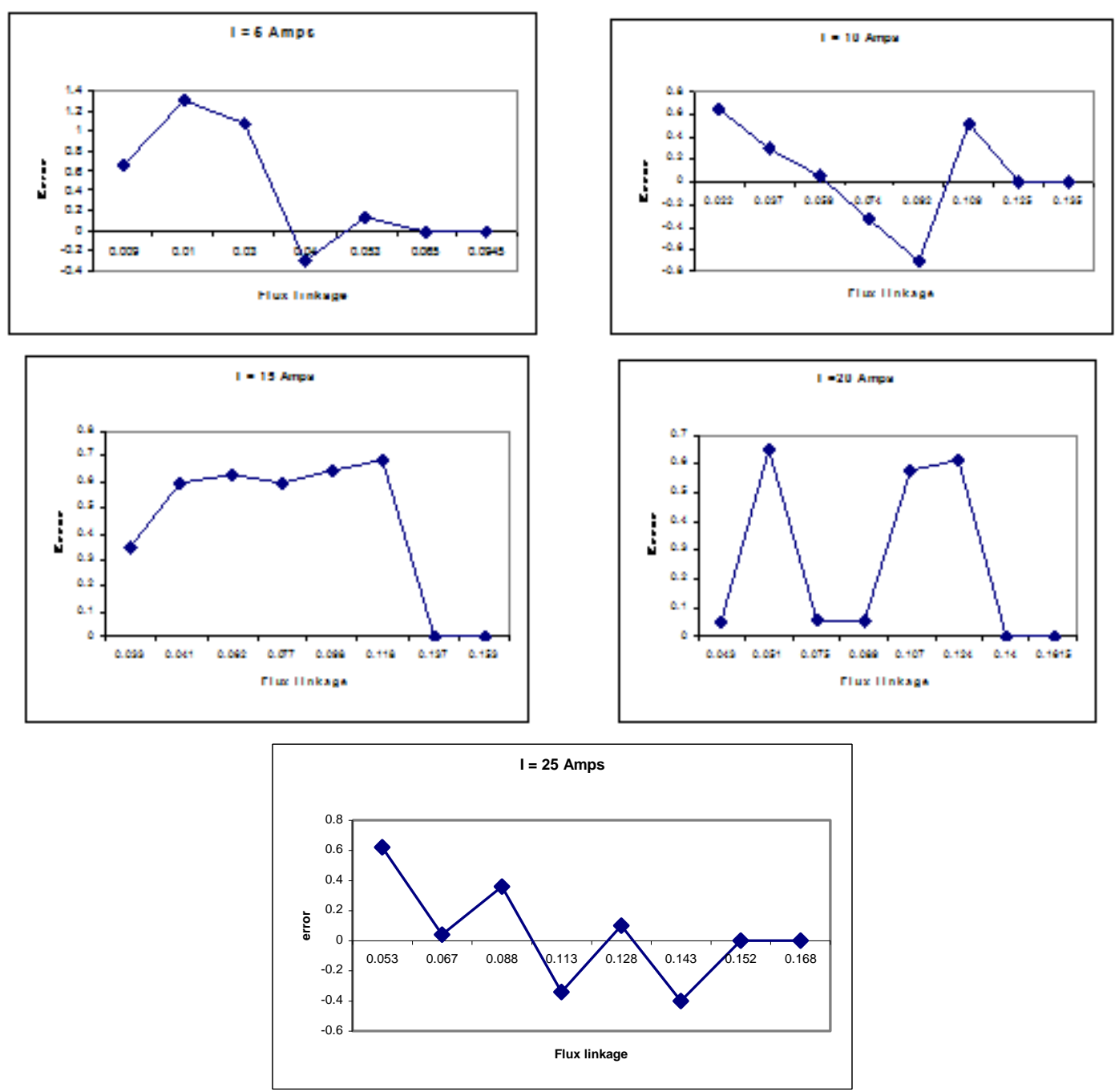

Fig.9. Error in theta values predicted from ANFIS model at different operating currents 


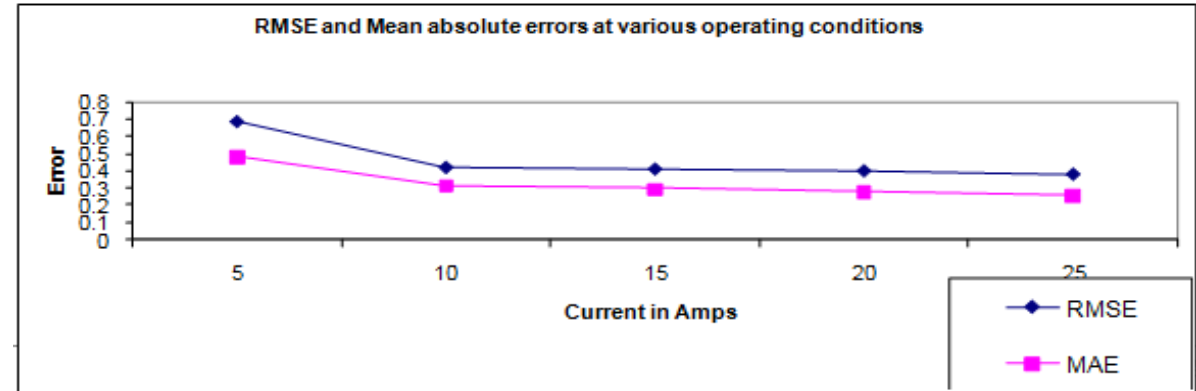

Fig.10. RMSE and MAE for ANFIS rotor position model

V. Conclusion

This paper has presented a computationally efficient modelling technique for a 3 phase, $6 / 4$ switched reluctance machine for obtaining the nonlinear rotor position model by means of adaptive neuro fuzzy inference system. The ANFIS rotor position model is setup and trained with the magnetization data of the machine. The results of ANFIS model are in excellent and close agreement with the actual data yielding negligible errors for the complete range of the test data. The investigations carried out in this paper prove that the proposed method is capable of estimating the rotor position models for SRM within acceptable accuracy limits and are sure to present a superior performance when applied to modelling, prediction and control. The accuracy and ease of rotor position estimation of this model validate that this technique can be applied to the real time control of SR machine and can be effectively utilized for obtaining the subsequent controller design.

\section{References}

[1] R.Krishnan.Switched reluctance motor drives. Modeling,Simulation,analysis,design and Applications Boca Raton FL:CRC.2001.

[2] A.Cheok and N.ertugrul, sensorless rotor position detection techniques in switched reluctance motor drives, in proc.Australian Universities Power Eng.Conf.,Perth,Australia,sep 1995.,pp.27-29.

[3] J.T.Bass,M.Eshani and T.J.E.Miller, Robust torque control of switched reluctance motor without shaft position sensor, IEEE trans.ind.Electron.,vol.IE-33,pp.212-216, 1986.

[4] P.P.Acarnley,R.J.Hill and C.W.Hooper, Detection of rotor position in stepping and switched reluctance motors by monitoring current waveforms, IEEE Trans.Ind.Electron.,Vol IE-32,no.3,pp.215-222,1985.

[5] S.K.Panda and G.Amaratunga, Switched reluctance motor drive without direct rotor position sensing, in IEEE IAS Annu.Meeting, 1990, pp.525-530.

[6] M.Eshani,I.Husain and A.B.Kulkarni, Elimination of discrete position sensor and current sensor in switched reluctance motor drives, IEEE Trans.Ind.Appl.,vol.28,no.1,pp.128-135,jan-feb.1992.

[7] J.P.Lyons,S.R.Macminn and M.A.Preston, Flux/current methods for SRM rotor position estimation in IEEE IAS Annu.Meeting,1991,pp.482-487.

[8] A.Lumsdaine,J.H.Lang and M.J.Balas, A state observer for reluctance motors, presented at the Incremental Motion Control Systems Symp.,Champaign,IL,1986.

[9] N.Ertugruland A.D.Cheok, Indirect angle estimation in switched reluctance motor drives using fuzzy logic based motor model, IEEE Trans.Power Electron., vol.15, no.6, pp.1029-1044, nov.2000.

[10] A.Bellini.F.Flippetti,G.Franceschini,C.Tassoni and P.Vas, Position sensorless control of a SRM drive using ANN techniques, in IEEE IAS Annu.Meeting,1998,pp.533-539.

[11] E.Mese and D.A.Torrey, An approach for sensorless position estimation for switched reluctance motors using artificial neural networks, IEEE Trans. Power electron. vol.17, no.1, pp.66-75, Jan.2002.

[12] K.Hornik,M.Stinchcomoe and H.White, Multilayer feedback networks are universal approximators, Neural Netw.vol.3.pp.359366,1989 .

[13] L.O.A.P.Henriques,L.G.B.Rolim,W.I.Suemitsu and J.A.Dente, Torque rippleminimization in a switched reluctance drive by neuro fuzzy compensation,, IEEE Trans.Magn.vol.36,no.5,pp.3592-3594,Sep.2000.

[14] S.Paramasivam,S.vijayan,M.Vasudevan,R.Arumugam and R.Krishnan, Real time verification of AI based rotor position estimation techniques for a 6/4 pole switched reluctance motor drive, IEEE Trans.Magn., Vol.43,no.7,pp.3209-3222, Jul.2007.

[15] Switched reluctance motor Design and Simulation software by Peter Omand Rasmussen 